
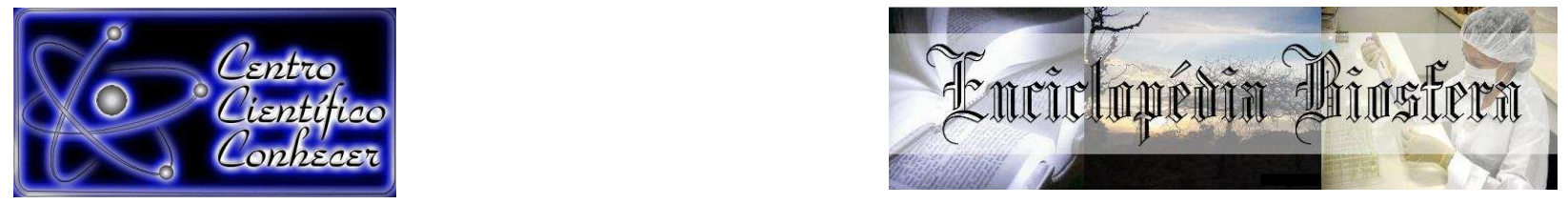

\title{
ATRIBUTOS DE SOLOS COESOS E NÃO COESOS NO COMPLEXO PETROQUÍMICO DO RIO DE JANEIRO, ITABORAÍ - RJ
}

\author{
Michele Ribeiro Ramos ${ }^{1}$; Alexandre Uhlmann ${ }^{2}$ Vander de Freitas Melo ${ }^{3}$ Gustavo \\ Ribas Curcio ${ }^{2}$; Eder Caglioni ${ }^{4}$ \\ 1 Professora Doutora Universidade do Oeste de Santa Catarina \\ (michele.ramos@unoesc.edu.br) Xanxerê-SC, Brasil. \\ 2 Pesquisador Doutor Embrapa Florestas Colombo - PR, Brasil. \\ 3 Professor Doutor Universidade Federal do Paraná. Curitiba - PR, Brasil. \\ 4 Doutorando em Engenharia Florestal da Universidade Federal do Paraná \\ 5 Curitiba - PR, Brasil.
}

Recebido em: 08/09/2015 - Aprovado em: 14/11/2015 - Publicado em: 01/12/2015
DOI: http://dx.doi.org/10.18677/Enciclopedia_Biosfera_2015_090

\begin{abstract}
RESUMO
Os solos coesos estão presentes em ampla distribuição geográfica, não estando limitado apenas ao tabuleiro costeiro. Desta forma, estudos de caracterização se fazem necessários para identificar as variações existentes, considerando que o caráter coeso se tem manifestado em geologias distintas. Outro fator é que apesar de ampla a literatura sobre solos coesos, ainda é inexistente a caracterização desses solos tendo como referência, na mesma área, um não coeso. O objetivo deste trabalho foi o de caracterizar os atributos morfológicos, químicos e físicohídricos de solos coesos e não coesos, em duas topossequências, desenvolvidos sob mesma condição climática e histórico de uso no Complexo Petroquímico do Rio de Janeiro (COMPERJ). Foram coletadas amostras deformadas e indeformadas para estudo dos atributos citados. Apesar da formação Macacu estar dissociada do grupo Barreiras cronologicamente, os solos desenvolvidos a partir dela apresentam características semelhantes. Entre os solos coesos e não coesos, morfologicamente são distintos, porém apresentam as mesmas restrições químicas. Contudo, há variações nos atributos físicos entre os solos com e sem o caráter em questão e, principalmente, dentro das classes coesas o terço superior se diferenciou do terço inferior.
\end{abstract}

PALAVRAS-CHAVE: Atributos químicos, Físico-hídrico, Morfologia

\section{ATRIBUTES MORPHOLOGICAL, PHYSICAL AND CHEMICAL CHARACTERISTICS OF COHESIVE AND NON-COHESIVE SOILS IN THE COMPLEXO PETROQUÍMICO DO RIO DE JANEIRO, ITABORAÍ - RJ.}

\begin{abstract}
Cohesive soils are very diverse, due to its wide distribution, mainly because the sedimentary deposits were worked for a long time during and after deposition. Thus, characterization studies are necessary to identify variations, whereas the cohesive character is manifested in distinctive geological Barreiras Group. Another factor is that despite the extensive literature on cohesive soils, is still scarce the characterization of these soils as a reference, in the same area of non-cohesive soils.
\end{abstract}


The objective of this study was to characterize morphological, chemical and physical attributes of two toposequence of cohesive soils and non-cohesive soils, developed under the same climatic conditions and land use history, in Itaboraí, RJ. Disturbed and undisturbed samples were collected to study the these attributes. Despite the Macacu Formation does not belong to Barreiras Group chronologically, the soils developed from it have similar characteristics. Non-cohesive and cohesive soils are morphologically distinct but have the same chemical restraints. However, the differences on physical attributes were marked between soils with and without the character in question and especially within different places on the landscape.

KEYWORDS: Chemical properties, Physical and water, Morphology

\section{INTRODUÇÃO}

O caráter coeso (EMBRAPA, 2013) é de extrema relevância por sua grande distribuição geográfica, proporcionando forte influência na dinâmica hídrica em diferentes classes de solos, situados em distintas posições nas paisagens. São ocupados para os mais diversos usos, pois além de ocuparem grandes extensões, são profundos e com teores de argila variando entre 15-95 \% (RAMOS et al., 2013) e ainda podem ser encontrados em relevo plano a ondulado.

Com relação às características químicas, são frequentemente distróficos, com altos valores de alumínio trocável, subsequentemente com baixo valor de $\mathrm{pH}$, sendo raros os registros de solos eutróficos (LIMA NETO et al., 2010; RAMOS et al., 2013). Os teores de carbono raramente ultrapassam $15 \mathrm{~g} \mathrm{~kg}^{-1}$ no horizonte mais superficial, chegando até $20 \mathrm{~g} \mathrm{~kg}^{-1}$, mesmo sob floresta (SILVA et al., 2014). Quanto às características físicas, na estação das chuvas, eles não apresentam restrições, contudo, no período seco o caráter coeso se expressa impondo restrições ao uso e manejo do solo. Destaca-se a elevada resistência à penetração, que se relaciona a falta de organização estrutural visível a olho nu, assumindo aspecto maciça/coesa (LIMA NETO et al., 2010). Elevados valores de densidade do solo, como consequência da expressiva redução da porosidade total, prejudicam a aeração e a absorção de nutrientes e ainda reduzem a condutividade hidráulica desses horizontes (DEDECEK et al., 2014), causa ainda a redução da profundidade efetiva e estrangulamento de raízes, dificultando a emergência de plântulas, que por consequência afeta a produtividade das culturas (SOUZA et al., 2008). Em uma pedossequência há alterações na dinâmica hídrica do solo, sendo, na maioria das vezes o terço inferior mais úmido que o terço superior (LIMA NETO 2010; DEDECEK et al., 2014), porém não trata-se de um comportamento exclusivo dos solos coesos.

Quanto a sua abrangência geográfica, há registros de solos similares no continente Africano e na Austrália (GIAROLA \& SILVA, 2002). Os primeiros são desenvolvidos a partir de sedimentos da formação Continental Terminal Africano, possivelmente por correspondência geológica das superfícies de extensão dos dois continentes (Sul-Americano e Africano) (RIBEIRO, 2007). No Brasil, o caráter ocorre predominantemente em domínio dos tabuleiros costeiros, no entanto, desde a década de cinquenta tem sido empregado para solos no Rio de Janeiro e Distrito Federal. Mas recentemente outros trabalhos tem relatado a presença de coesão em solos originados de diversos materiais geológicos (SILVA et al., 2009; GOMES et al., 2012).

O objetivo deste trabalho foi caracterizar os atributos químicos, físicos e morfológicos de solos com diferentes materiais de origem, desenvolvidos sob mesma condição climática e histórico de uso, no município de Itaboraí, RJ (Complexo petroquímico do Rio de Janeiro - COMPERJ). 


\section{MATERIAL E MÉTODOS}

\section{Área de estudo}

O estudo foi realizado no município de Itaboraí, Estado do Rio de Janeiro. De acordo com IBGE (Instituto Brasileiro de Geografia e Estatística) o clima da região é Tropical, quente e úmido, com 1 a 2 meses secos, com temperatura média acima de $18^{\circ} \mathrm{C}$ em todos os meses do ano. No verão, o calor e a umidade são muito expressivos com elevada precipitação $(1463 \mathrm{~mm})$. Porém, no inverno há redução significativa da umidade, temperatura e pluviometria, especialmente entre os meses de junho a agosto (GONÇALVES, 2014). O mesmo autor classifica o clima da região como pertencente ao clima "Aw" de Köppen (clima tropical com estação seca).

As áreas foram selecionadas dentro do COMPERJ, inserida na região sedimentar da Baía de Guanabara, que juntamente com outras bacias formam o rift continental do Sudeste do Brasil (RICCOMINI et al., 2004). A estratigrafia da Bacia é constituída por rochas metamórficas da Formação São Fidélis do Proterozóico e sedimentos da Formação Macacu do período Eoceno/Oligoceno, e ainda sedimentos inconsolidados do Holoceno.

O histórico de uso das áreas é acompanhado do desflorestamento desde o período colonial seguido de vários ciclos de cultivos, sendo principalmente de Citrus e canavial (CABRAL \& FISZON, 2004; CABRAL, 2008), posteriormente o uso por pastagens. Desde 2007 as áreas encontram-se em estágio de regeneração, compondo uma produção de biomassa das gramíneas que chegam a valores de até 18 toneladas por hectares (SILVA et al., 2014).

$\mathrm{Na}$ área do COMPERJ é encontrada grande diversidade de solos, porém para este estudo foram selecionadas duas topossequências. A primeira constituída por solos coesos (Argissolo Amarelo Distrocoeso típico relevo ondulado- LAx - perfil 1; Latossolo Amarelo Distrocoeso típico relevo suave ondulado - LAx, terço superior perfil 02). A segunda é composta por solos sem o caráter coeso (Argissolos Vermelho-Amarelo Distróficos típicos relevo forte ondulado - PVA - perfis 03 e 04). Ambas ocupadas com pastagem até 2007.

\section{Análises de solo}

A caracterização morfológica foi feita segundo SANTOS et al., (2005). Amostras de solos de todos os horizontes dos perfis, depois de secas ao ar, foram homogeneizadas e passada em peneiras de malha $2 \mathrm{~mm}$, e analisadas quanto à granulometria e às características químicas, de acordo com EMBRAPA (1997). As cinco frações da areia (muito grossa: 2-1 mm; grossa: 1- 0,5 mm; média: 0,5-0,25 $\mathrm{mm}$; fina: $0,25-0,1 \mathrm{~mm}$; muito fina: $0,1-0,05 \mathrm{~mm}$ ) foram determinadas seguindo critério de USDA (1993).

Para a análise físico-hídrica, coletaram-se três amostras indeformadas por horizonte em anéis de aço de $65 \mathrm{~cm}^{3}$ de volume, e determinadas, a densidade do solo, macroporosidade, porosidade total, microporosidade, porosidade de aeração, bem como água disponível, umidade à capacidade de campo, umidade no ponto de murcha permanente e condutividade hidráulica saturada.

Todos esses parâmetros foram determinados após a saturação plena dos anéis (anéis $\varnothing 49 \times 53 \mathrm{~mm}$ em aço inox), por período de 48 horas, pesados e colocados sobre membranas porosas no interior dos Extratores de Richards. Foi 
considerada a tensão de $10 \mathrm{KPa}$ para a determinação da capacidade de campo; $1500 \mathrm{KPa}$ para o ponto de murcha permanente. A drenagem do excesso de água na altura de $0,60 \mathrm{~m}$ da bancada foi utilizada para determinar a macroporosidade nas amostras. A porosidade total foi considerada o peso da massa saturada menos 0 peso da massa seca a $105^{\circ} \mathrm{C}$. A microporosidade foi considerada a diferença entre a porosidade total e a macroporosidade. A água disponível foi definida como a diferença de umidade entre a capacidade de campo $(-10 \mathrm{kPa})$ e o ponto de murcha permanente $(-1500 \mathrm{kPa})$. E finalmente a porosidade de aeração foi determinada considerando a diferença de umidade entre a porosidade total e a umidade na capacidade de campo, definida na pressão de $-10 \mathrm{kPa}$. A condutividade hidráulica saturada foi obtida utilizando o método descrito no manual da EMBRAPA (1997).

Foram calculadas a capacidade campo considerando 10 e 15\% de porosidade de aeração e posteriormente recalculados os teores de água disponível considerando os novos valores de capacidade de campo.

\section{RESULTADOS E DISCUSSÃO}

Quanto a cor, nos solos coesos foram identificados matizes mais amarelos que 9YR (Tabela 1) com cromas e valores muito elevados em coerência à identificação feita por outros autores (VIEIRA et al., 2012), contudo os solos de terço superior possuem tonalidades mais vermelhas que os de terço inferior. As condições de menor umidade e menores teores de matéria orgânica favorecem à formação de hematita em detrimento a goethita. Enquanto que nos solos desenvolvidos de rochas metamórficas, mais especificamente em Argissolos Vermelho-Amarelos (PVA) predominaram matizes entre 5 e 7,5YR. Essas diferenças nos cromas, no primeiro momento, foram devidas, essencialmente, ao material de origem e depois ao posicionamento na paisagem. Essas diferenças de cotas, favorecem os fluxos de superfície e subsuperfície, ocasionado por processos erosivos. Enquanto a consistência, de um modo geral, friável e muito friável, com estrutura moderada em todos os horizontes, para todos os perfis, independentemente da posição na paisagem (Tabela 1).

Em contrapartida, os solos desenvolvidos a partir de rochas sedimentares apresentaram consistência friável/firme no horizonte superficial, muito firme no transicional e nos demais horizontes, firme no perfil de terço superior. E esta variou no terço inferior, sendo friável/firme no horizonte mais superficial, firme no transicional, e friável/firme nos demais horizontes. Essa variação é a principal característica morfológica dos solos coesos.

Vale salientar que nesses mesmos solos foi verificado maior friabilidade em horizontes pertencentes ao perfil situado no terço inferior, possivelmente pelo maior acúmulo de água (Tabela 1). VIEIRA et al., (2012) encontraram diferenças nas características morfológicas em diferentes posições na encosta, corroborando com o encontrado neste trabalho, evidenciando a influência dos fluxos hídricos na expressão do caráter, ou seja, a presença de umidade tende a diminuir a expressão do caráter.

Quanto à estrutura do horizonte $\mathrm{B}$, foram encontradas moderada/fraca média e grande blocos subangulares nos solos coesos, enquanto que nos não coesos, moderada média grande blocos subangulares. Desta forma, quanto as características morfológicas, o material de origem diferenciou os tipos de solos quanto a cor (valor e croma) e a consistência. 
TABELA 1 - Caracterização morfológica de solos provenientes de rochas sedimentares e metamórficas de terço superior e inferior, localizados no município de Itaboraí /RJ

\begin{tabular}{|c|c|c|c|c|c|c|c|}
\hline Mat. Origem & Altitude (m) & Perfil/Posição & Classe & Horiz. & Prof. $(\mathrm{cm})$ & cor & Descrição \\
\hline \multicolumn{8}{|c|}{ Topossequência 01} \\
\hline \multirow{4}{*}{$\begin{array}{c}\text { Rochas } \\
\text { Sedimentares - } \\
\text { Formação } \\
\text { Macacu - } \\
\text { Grupo } \\
\text { Barreiras }\end{array}$} & \multirow{4}{*}{29} & \multirow{2}{*}{ Perfil 01} & \multirow{4}{*}{$\begin{array}{l}\text { Argissolo } \\
\text { Amarelo } \\
\text { Distrocoeso } \\
\text { típico }\end{array}$} & Ap & $0-18$ & $\begin{array}{l}\text { (10YR3/2) } \\
\text { bruno- } \\
\text { acinzentado } \\
\text { muito escuro } \\
\end{array}$ & $\begin{array}{l}\text { franco-arenoso; moderada/fraca pequena granular; macia, } \\
\text { friável/firme, ligeiramente plástico e ligeiramente pegajoso; } \\
\text { transição clara e plana. }\end{array}$ \\
\hline & & & & BAx & $18-32$ & $\begin{array}{l}(10 Y R 4 / 5) \\
\text { bruno-amarelo } \\
\text { escuro }\end{array}$ & $\begin{array}{c}\text { franco-argilo-arenoso; fraca/moderada média e grandes blocos } \\
\text { subangulares que se desfaz em moderada fraca e pequena e muito } \\
\text { pequena granular; muito firme, plástico e pegajoso; transição } \\
\text { gradual e plana. }\end{array}$ \\
\hline & & \multirow{2}{*}{ Superior } & & Btx1 & $32-61$ & $\begin{array}{l}(10 \mathrm{YR} 5 / 7) \\
\text { bruno- } \\
\text { amarelado }\end{array}$ & $\begin{array}{l}\text { franco-argilo-arenoso; fraca/moderada grandes blocos } \\
\text { subangulares que se desfaz em moderado pequena muito pequena } \\
\text { granular; firme, plástico e pegajoso; transição difusa e plana }\end{array}$ \\
\hline & & & & Btx2 & $61-75^{+}$ & $\begin{array}{l}\text { (9YR } 5 / 8) \\
\text { bruno- } \\
\text { amarelado } \\
\end{array}$ & $\begin{array}{l}\text { argilo-arenoso; fraca grandes blocos subangulares que se desfaz } \\
\text { em moderada pequena e muito pequena granular; firme, plástico e } \\
\text { pegajoso. }\end{array}$ \\
\hline \multirow{4}{*}{$\begin{array}{c}\text { Rochas } \\
\text { Sedimentares - } \\
\text { Formação } \\
\text { Macacu - } \\
\text { Grupo } \\
\text { Barreiras }\end{array}$} & \multirow{4}{*}{19} & \multirow{3}{*}{ Perfil 02} & \multirow{4}{*}{$\begin{array}{l}\text { Latossolo } \\
\text { Amarelo } \\
\text { Distrocoeso } \\
\text { Típico }\end{array}$} & Ap & $0-22$ & $\begin{array}{l}\text { (10YR } 3 / 2) \\
\text { bruno- } \\
\text { acinzentado } \\
\text { muito escuro }\end{array}$ & $\begin{array}{l}\text { franco-argilo-arenoso; moderada pequena média blocos } \\
\text { subangulares que se desfaz em moderada fraca pequena granular; } \\
\text { friável/firme, ligeiramente plástico e ligeiramente pegajoso; } \\
\text { transição clara e ondulada. }\end{array}$ \\
\hline & & & & BAx & $22-36$ & $\begin{array}{l}\text { (10YR 4/5) } \\
\text { bruno- } \\
\text { amarelado } \\
\text { escuro }\end{array}$ & $\begin{array}{c}\text { franco-argilo-arenoso; fraca/moderada grandes blocos } \\
\text { subangulares que se desfaz em moderada fraca pequena muito } \\
\text { pequena granular; firme plástico e pegajoso; transição gradual e } \\
\text { plana. }\end{array}$ \\
\hline & & & & $B w x 1$ & $36-74$ & $\begin{array}{l}(10 Y R 5 / 7) \\
\text { bruno- } \\
\text { amarelado }\end{array}$ & $\begin{array}{c}\text { franco-argilo-arenoso; fraca grandes blocos subangulares que se } \\
\text { desfaz em moderada muito pequena granular; friável/firme, plástico } \\
\text { e pegajoso; transição difusa e plana. }\end{array}$ \\
\hline & & Inferior & & Bwx2 & $74-102^{+}$ & $\begin{array}{l}(10 Y R 5 / 8) \\
\text { bruno- } \\
\text { amarelado }\end{array}$ & $\begin{array}{c}\text { franco-argilo-arenoso; fraca grandes blocos subangulares que se } \\
\text { desfaz em moderada muito pequena granular; friável/firme, plástico } \\
\text { e pegajoso. }\end{array}$ \\
\hline
\end{tabular}

continua 
TABELA 1 - Caracterização morfológica de solos provenientes de rochas sedimentares e metamórficas de terço superior e inferior, localizados no município de Itaboraí/RJ.

\begin{tabular}{|c|c|c|c|c|c|c|c|}
\hline Mat. Origem & Altitude $(\mathrm{m})$ & Perfil/Posição & Classe & Horiz. & Prof. (cm) & cor & Descrição \\
\hline \multicolumn{8}{|c|}{ Topossequência 02} \\
\hline \multirow{4}{*}{$\begin{array}{l}\text { granito-gnaisse } \\
\text { - Formação } \\
\text { São Fidélis - } \\
\text { Proterozóico }\end{array}$} & \multirow{4}{*}{52} & \multirow[t]{2}{*}{ Perfil 03} & \multirow{4}{*}{$\begin{array}{l}\text { Argissolo } \\
\text { Vermelho- } \\
\text { Amarelo } \\
\text { Distrófico } \\
\text { Típico }\end{array}$} & Ap & $0-11$ & $\begin{array}{l}(10 Y R 3 / 3) \\
\text { bruno-escuro }\end{array}$ & $\begin{array}{c}\text { franco-argilo-arenoso; moderada pequena e média blocos } \\
\text { subangulares que se desfaz em moderada pequena fraca granular; } \\
\text { friável, ligeiramente plástico e ligeiramente pegajoso; transição } \\
\text { clara e plana. }\end{array}$ \\
\hline & & & & BA & $11-34$ & $\begin{array}{l}(7,5 Y R 4 / 6) \\
\text { bruno-forte }\end{array}$ & $\begin{array}{l}\text { argilo-arenoso; moderada pequena e média blocos que se desfaz } \\
\text { em moderada pequena granular; firme/friável, plástico e pegajoso; } \\
\text { transição gradual plana. }\end{array}$ \\
\hline & & \multirow{2}{*}{ Superior } & & $\mathrm{Bt} 1$ & $34-55$ & $\begin{array}{l}(7,5 Y R 5 / 7) \\
\text { bruno-forte }\end{array}$ & $\begin{array}{l}\text { argilo-arenoso; moderada pequena muito pequena blocos; } \\
\text { friável/muito friável, plástico e pegajoso; transição difusa e plana. }\end{array}$ \\
\hline & & & & $\mathrm{Bt} 2$ & $55-98+$ & $\begin{array}{l}(7,5 \text { YR } 5 / 7) \\
\text { bruno-forte }\end{array}$ & $\begin{array}{l}\text { argiloso; moderada pequena muito pequena granular; friável, } \\
\text { plástico e pegajoso. }\end{array}$ \\
\hline \multirow{4}{*}{$\begin{array}{l}\text { granito-gnaisse } \\
\text { - Formação } \\
\text { São Fidélis - } \\
\text { Proterozóico }\end{array}$} & \multirow{4}{*}{20} & & \multirow{4}{*}{$\begin{array}{c}\text { Argissolo } \\
\text { Vermelho- } \\
\text { Amarelo } \\
\text { Distrófico } \\
\text { Típico }\end{array}$} & Ap & $0-16$ & $\begin{array}{l}(10 Y R 3 / 3) \\
\text { bruno-escuro }\end{array}$ & $\begin{array}{l}\text { argilo-arenoso; moderada pequena e média blocos subangulares } \\
\text { que se desfaz em moderada pequena/fraca granular; friável, } \\
\text { ligeiramente plástico e ligeiramente pegajoso; transição clara plana. }\end{array}$ \\
\hline & & Perfil 04 & & BA & $16-40$ & $\begin{array}{l}\text { (6YR } 4 / 6) \\
\text { bruno-forte a } \\
\text { vermelho- } \\
\text { amarelado }\end{array}$ & $\begin{array}{l}\text { argiloso; moderada pequena média blocos subangulares que se } \\
\text { desfaz em moderada pequena granular; friável, plástico e pegajoso; } \\
\text { transição gradual e plana. }\end{array}$ \\
\hline & & \multirow{2}{*}{ Inferior } & & $\mathrm{Bt} 1$ & $40-65$ & $\begin{array}{l}(5 Y R \quad 4,5 / 6) \\
\text { bruno- } \\
\text { avemelhado }\end{array}$ & $\begin{array}{c}\text { muito argiloso; moderada pequena blocos subangulares que se } \\
\text { desfaz em moderada pequena granular; friável, plástico e pegajoso; } \\
\text { transição difusa e plana. }\end{array}$ \\
\hline & & & & Bt2 & $65-113$ & $\begin{array}{l}(5 Y R 5 / 6) \\
\text { bruno- } \\
\text { avermelhado }\end{array}$ & $\begin{array}{c}\text { muito argiloso; moderada grande média blocos subangulares que } \\
\text { se desfaz em moderada/forte pequena granular; friável/muito } \\
\text { friável, plástico e pegajoso; transição difusa e plana. }\end{array}$ \\
\hline
\end{tabular}


Nos solos estudados a fração areia foi a dominante, especialmente naqueles derivados de rochas sedimentares, com valores entre 500 e $600 \mathrm{~g} \mathrm{~kg}^{-1}$ favorecendo a textura franco-argilo-arenosa e argilo-arenosa (Tabela 1 e 2). Foi verificado incremento de argila no terço inferior em relação ao superior e no horizonte mais subsuperficial $\left(\mathrm{BwX}_{2}\right)$. Em oposição, nos solos não coesos a fração argila se destacou, gerando solos com textura argilosa/muito argilosa principalmente no terço inferior.

TABELA 2 - Resultados das análises químicas e granulométricas de solos provenientes de rochas sedimentares e metamórficas em terço superior e inferior de encosta, município de Itaboraí RJ.

\begin{tabular}{|c|c|c|c|c|c|c|c|c|c|c|c|}
\hline \multicolumn{2}{|c|}{ Horizontes } & \multirow{2}{*}{\multicolumn{3}{|c|}{$\begin{array}{c}\text { Composição } \\
\text { granulométrica } \\
\mathrm{g} \mathrm{kg}^{-1}\end{array}$}} & \multirow{3}{*}{$\begin{array}{c}\text { Relação } \\
\text { Silte/ } \\
\text { Argila }\end{array}$} & \multirow{3}{*}{$\begin{array}{c}\mathrm{pH} \\
\mathrm{CaCl}_{2}\end{array}$} & \multirow{3}{*}{$\mathrm{g} \mathrm{dm}^{-3}$} & \multirow[t]{2}{*}{$\begin{array}{c}\text { Valor } \\
\text { S }\end{array}$} & \multirow[t]{3}{*}{$\begin{array}{c}\text { Valor } \\
\mathrm{T}\end{array}$} & \multirow{3}{*}{$\begin{array}{c}\text { Valor } \\
\text { V } \\
\%\end{array}$} & \multirow{3}{*}{$\begin{array}{c}\text { Valor } \\
\text { m } \\
\%\end{array}$} \\
\hline \multirow{2}{*}{ Simb. } & \multirow{2}{*}{$\begin{array}{l}\text { Prof. } \\
\text { (cm) }\end{array}$} & & & & & & & & & & \\
\hline & & areia & silte & argila & & & & $\mathrm{cmo}$ & & & \\
\hline \multicolumn{12}{|c|}{ Pedossequência 01 - Perfil 01 (LAx) - Terço superior } \\
\hline Ap & $0-18$ & 691 & 109 & 200 & 0,55 & 3,9 & 20,2 & 1,20 & 8,4 & 14 & 45 \\
\hline$B A x$ & $18-32$ & 600 & 174 & 225 & 0,78 & 3,6 & 11,5 & 0,45 & 7,6 & 6 & 80 \\
\hline $\mathrm{Btx}_{1}$ & $32-61$ & 559 & 116 & 325 & 0,36 & 3,7 & 5,1 & 0,33 & 7,5 & 4 & 86 \\
\hline $\mathrm{Btx}_{2}$ & $61-75^{+}$ & 519 & 30 & 450 & 0,07 & 3,7 & 2,4 & 0,22 & 6,0 & 4 & 90 \\
\hline \multicolumn{12}{|c|}{ Pedossequência 01 - Perfil 02 (LAx) - Terço inferior } \\
\hline$A p$ & $0-22$ & 513 & 211 & 275 & 0,77 & 3,5 & 12,4 & 0,34 & 7,5 & 5 & 86 \\
\hline$B A x$ & $22-36$ & 529 & 120 & 350 & 0,34 & 3,6 & 12,4 & 0,31 & 7,5 & 4 & 87 \\
\hline$B w x_{1}$ & $36-74$ & 585 & 89 & 325 & 0,28 & 3,7 & 2,4 & 0,31 & 6,5 & 5 & 87 \\
\hline$B w x_{2}$ & $74-102^{+}$ & 555 & 95 & 350 & 0,27 & 3,7 & 3,3 & 0,31 & 6,5 & 5 & 87 \\
\hline \multicolumn{12}{|c|}{ Pedossequência 02 - Perfil 03 (PVA) - Terço superior } \\
\hline Ap & $0-11$ & 453 & 272 & 275 & 0,99 & 3,7 & 24,3 & 0,95 & 7,6 & 12 & 86 \\
\hline BA & $11-34$ & 338 & 137 & 525 & 0,26 & 3,8 & 12,4 & 0,33 & 6,5 & 5 & 85 \\
\hline $\mathrm{Bt}_{1}$ & $34-55$ & 338 & 121 & 450 & 0,47 & 3,8 & 9,6 & 0,31 & 6,5 & 5 & 84 \\
\hline $\mathrm{Bt}_{2}$ & $55-98^{+}$ & 310 & 139 & 550 & 0,25 & 3,8 & 6,0 & 0,21 & 6,0 & 3 & 88 \\
\hline \multicolumn{12}{|c|}{ Pedossequência 02 - Perfil 04 (PVA) - Terço inferior } \\
\hline Ap & $0-16$ & 484 & 165 & 350 & 0,47 & 3,7 & 22,2 & 0,68 & 7,3 & 9 & 67 \\
\hline BA & $16-40$ & 304 & 146 & 550 & 0,27 & 3,7 & 6,0 & 0,32 & 6,1 & 5 & 85 \\
\hline $\mathrm{Bt}_{1}$ & $40-65$ & 206 & 118 & 675 & 0,18 & 3,9 & 7,8 & 0,21 & 6,0 & 3 & 89 \\
\hline $\mathrm{Bt}_{2}$ & $65-113$ & 269 & 55 & 675 & 0,08 & 3,9 & 9,6 & 0,21 & 5,2 & 4 & 88 \\
\hline
\end{tabular}

Por outro lado, nos solos desenvolvidos de rochas metamórficas, os teores de areia oscilaram entre $206 \mathrm{~g} \mathrm{~kg}^{-1}$ a $484 \mathrm{~g} \mathrm{~kg}^{-1}$. Em solos provenientes das rochas sedimentares, os teores de argila situaram-se em $200 \mathrm{~g} \mathrm{~kg}^{-1}$ no horizonte superficial, chegando a dobrar a quantidade nos horizontes subsuperficiais, sendo que no LAx (terço inferior) esses valores atingiram $350 \mathrm{~g} \mathrm{~kg}^{-1}$ (Tabela 2).

Característica importante a ser considerada é a predominância relativa dos grãos de areia dos solos coesos, e principalmente a equitatividade das frações grossa, média e fina (Tabela 3) aliada as frações mais finas de silte e argila podem favorecer a justaposição de partículas (GOMES et al., 2014). LIMA et al., (2004) afirmam que a maior variabilidade granulométrica da areia aliada a maior equitatividade das frações favorece o reajuste entre as partículas de areia e, por conseguinte das frações silte e argila. Os teores de argila dos solos não coesos atingiram valores superiores a $400 \mathrm{~g} \mathrm{~kg}^{-1}$ constituindo texturas que vão desde argilosa a muito argilosa (Tabela 2). Cabe ressaltar que os perfis de terço inferior, sobretudo os derivados de granito-gnaisse são bem mais argilosos que os de terço superior, indicando possível fluxo de argila das áreas mais altas para as mais baixas, ou mesmo diferenciações do próprio material de origem, em menor escala. A maioria dos solos coesos descritos na literatura apresenta o predomínio de texturas médias em subsuperfície, franco-arenosa, franco-argilo-arenosa e argilo-arenosa 
(GIAROLA et al., 2001). Considerando que se trata de solos desenvolvidos a partir de rochas sedimentares, o incremento de argila nos solos coesos pode estar relacionado a proximidade de solos ou materiais mais argilosos situados em cotas superiores, indicando uma possível migração de sedimentos finos de posições mais altas da paisagem para as mais baixas.

TABELA 3 - Fracionamento da fração areia de solos desenvolvidos de rochas sedimentares da formação Macacu e metamórficas da Formação são Fidélis*.

\begin{tabular}{|c|c|c|c|c|c|c|}
\hline \multirow{2}{*}{$\begin{array}{l}\text { Horiz. } \\
\text { Simb. }\end{array}$} & \multirow{2}{*}{$\begin{array}{c}\text { Prof. } \\
\mathrm{cm}\end{array}$} & \multicolumn{5}{|c|}{ Areia \% } \\
\hline & & MG & $\mathrm{G}$ & M & $\mathrm{F}$ & MF \\
\hline \multicolumn{7}{|c|}{ Pedossequência 01 - Perfil 01 (PAx) - Terço Superior } \\
\hline Ap & $0-18$ & 13 & 22 & 28 & 30 & 7 \\
\hline$B A x$ & $18-32$ & 10 & 21 & 33 & 31 & 5 \\
\hline $\mathrm{Btx}_{1}$ & $32-61$ & 6,3 & 18 & 39 & 31 & 5,7 \\
\hline $\mathrm{Btx}_{2}$ & $61-75+$ & 8 & 20 & 37 & 30 & 5 \\
\hline \multicolumn{7}{|c|}{ Pedossequência 01 - Perfil 02 (LAx) - Terço Inferior } \\
\hline Ap & $0-22$ & 9 & 21 & 27 & 32 & 11 \\
\hline$B A x$ & $22-36$ & 10 & 25 & 35 & 25 & 5 \\
\hline $\mathrm{Bwx}_{1}$ & $36-74$ & 5 & 19 & 46 & 24 & 6 \\
\hline $\mathrm{Bw}_{2}$ & $74-102+$ & 7 & 23 & 37 & 27 & 6 \\
\hline \multicolumn{7}{|c|}{ Pedossequência 02 - Perfil 03 (PVA) - Terço Superior } \\
\hline Ap & $0-11$ & 10 & 32 & 30 & 22 & 6 \\
\hline BA & $11-34$ & 10 & 30 & 36 & 19 & 5 \\
\hline $\mathrm{Bt}_{1}$ & $34-55$ & 3 & 15 & 39 & 35 & 8 \\
\hline $\mathrm{Bt}_{2}$ & $55-98+$ & 3 & 15 & 47 & 30 & 5 \\
\hline \multicolumn{7}{|c|}{ Pedossequência 02 - Perfil 04 (PVA) - Terço Inferior } \\
\hline Ap & $0-16$ & 7 & 30 & 32 & 24 & 7 \\
\hline BA & $16-40$ & 5 & 21 & 41 & 26 & 7 \\
\hline $\mathrm{Bt}_{1}$ & $40-65$ & 3 & 17 & 43 & 36 & 1 \\
\hline $\mathrm{Bt}_{2}$ & $65-113+$ & 5 & 21 & 43 & 26 & 5 \\
\hline
\end{tabular}

Fracionamento da areia em \%: MG - muito grossa (2-1 mm), G - grossa (1-0,5 mm), M - média (0,5-0,25 mm), F - fina $(0,25-0,1 \mathrm{~mm})$ e MF - muito fina $(0,1-0,05 \mathrm{~mm})$

A grande diversificação textural encontrada na literatura também pode ser justificada em razão da imensa variação dos sedimentos que compõem os materiais de origem sedimentados. MORAIS et al. (2006), verificaram depósitos com inúmeros fácies. Ademais, variações nos tipos e intensidades dos processos pedogenéticos podem justificar a variação textural.

De um modo geral os solos das pedossequências estudadas apresentaram baixa relação silte/argila (menor que 0,6 ), indicando forte intemperismo (Tabela 2). Resultados semelhantes foram encontrados por MOREAU et al. (2006), CALEGARI e MARCOLIN (2014).

Em geral, independente do material de origem, os solos são fortemente dessaturados por bases (V\% menor que 6), com baixa CTC (8-5) e valores de $\mathrm{pH}$ $\mathrm{CaCl}_{2}$ inferiores a 4 (Tabela 2). A saturação por alumínio trocável dos horizontes subsuperficiais está acima de $80 \%$ indicando forte caráter álico e a matéria orgânica é o principal responsável pela CTC dos horizontes superficiais. Ou seja, o intemperismo resultou em solos de baixa fertilidade, independente do material de origem.

Os teores de matéria orgânica foram distintos entre os solos. O horizonte superficial do solo coeso de terço superior armazenou muito mais carbono que o de terço inferior. Na pedossequência não coesa o solo do terço superior apresentou também maior teor de carbono orgânico que o solo de terço inferior. Este pode ser justificado em função da maior umidade presente em solos situados em posições ENCICLOPÉDIA BIOSFERA, Centro Científico Conhecer - Goiânia, v.11 n.22; p.367 
mais baixas a qual predispõe uma maior retirada seletiva de materiais coloidais por processos erosivos (VIEIRA et al., 2012).

Em geral, as densidades dos solos coesos foram acima de $1,5 \mathrm{Mg} \mathrm{m}^{-3}$ (Tabela 4), com exceção apenas do horizonte superficial do perfil de terço superior, enquanto que nos solos da pedossequência não coesa, todos estão abaixo do valor citado acima.

Na Figura 1, é observada a variação decrescente da densidade nos perfis (P1 e P2) de solos coesos, onde as linhas tendem ao lado direito, principalmente o P1 (terço superior), e menos acentuado no P2 (terço inferior), evidenciando que o terço superior a coesão é maior que no terço inferior. Em contrapartida, nos perfis não coesos ocorre o inverso. Da mesma forma, o perfil de terço superior apresenta menor variação da densidade em relação ao de terço inferior, que tende a ser menos denso.

A tendência observada na Figura 1, considerando a densidade do solo, mostra que a coesão é fortemente influenciada pela posição na encosta e o material de origem é determinante para esse caráter, pois as duas pedossequências apresentam mesmo histórico de uso e ambiente de formação. Esses resultados encontram-se de acordo com MOREAU et al. (2006).

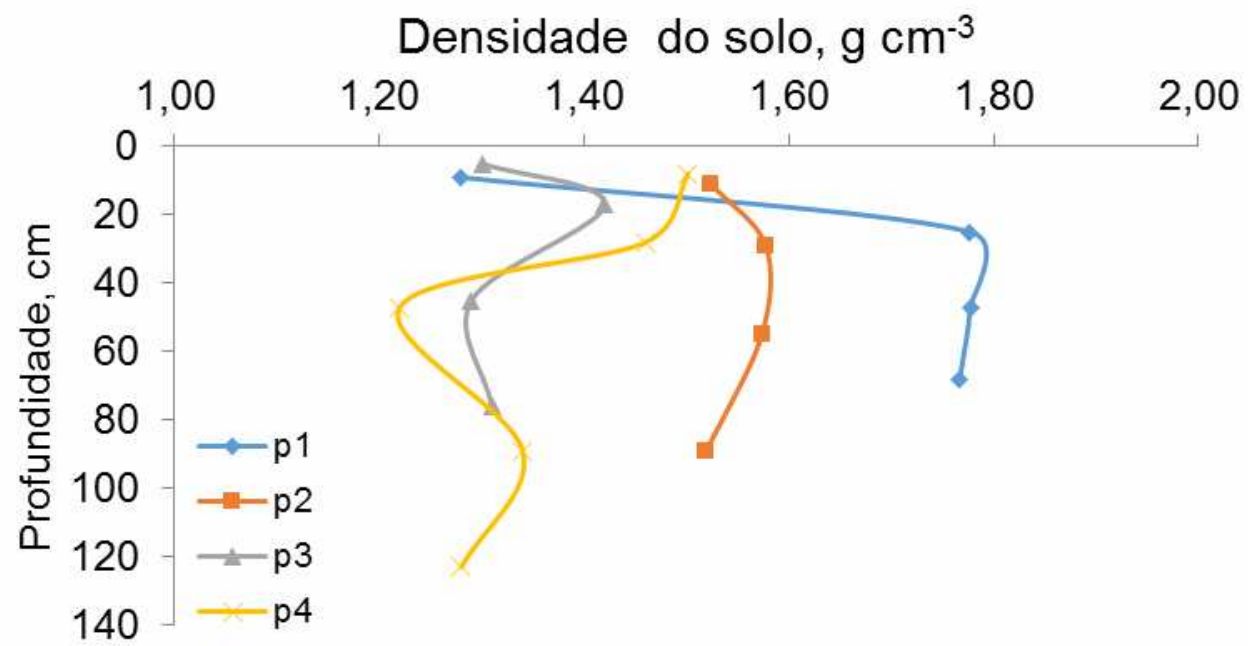

FIGURA 1 - Densidade de solos coesos (p1 - perfil 1 terço superior e p2 - perfil 2 terço inferior) e não coesos (p3 - perfil 3 terço superior e p4 - perfil 4 terço inferior) em relação a posição da paisagem e em profundidade.

Foi observado aumento da densidade nos horizontes subsuperficiais dos solos coesos, e nos não coesos o processo contrário, indicando que no primeiro caso, a matéria orgânica e a umidade atuaram como agentes amenizadores da densidade, principalmente no perfil de terço superior, já que no terço inferior essa tendência não foi verificada. Nos perfis 3 e 4, não coesos, os horizontes superficiais estão mais compactados que os subjacentes. Neste caso, esse resultado pode ser produto de intenso uso dessas áreas que datam desde o período da colonização (CABRAL, 2008).

A porosidade de aeração (PA) trata-se da fase do solo não ocupada por líquidos e sólidos, estando intimamente relacionada com o crescimento das raízes, sendo que as mesmas necessitam, no mínimo, de 10 a $15 \%$ de ar para desenvolverem suas funções fisiológicas normais (GUEDES FILHO et al., 2015). Porém esse valor varia de espécie para espécie, e ainda, tende a diminuir em profundidade no solo. 
Com base na explanação acima, foi verificado que entre os solos coesos a porosidade de aeração foi mais restritiva no solo de terço superior do que para o inferior (Tabela 4), ou seja, as condições para crescimento de raízes são muito mais limitantes no LAx (terço superior) do que no LAx (terço inferior). Nos PVA não coesos, foram encontradas as mesmas limitações de aeração, abaixo de $0,15 \mathrm{~m}^{3} \mathrm{~m}^{-3}$ porém dentro dos $0,10 \mathrm{~m}^{3} \mathrm{~m}^{-3}$ que é também citado na literatura como ainda ideal para o desenvolvimento das plantas.

Para a porosidade total, macroporosidade e microporosidade nas classes de solos coesas têm-se no horizonte superficial que a maior parte da porosidade total é composta por microporos e nos horizontes subsuperficiais esse valor representa mais de $90 \%$. Porém, entre os terços esses valores não foram diferentes, porosidade total entre 0,39 a $0,49 \mathrm{~m}^{3} \mathrm{~m}^{-3}$ (Tabela 4). $O$ volume de poros exerce forte influencia no desenvolvimento de raiz, sendo relacionada à absorção de nutrientes e à velocidade de infiltração da água (RAMOS et al., 2013; DEDECEK et al., 2014). Os mesmos atributos para as classes de solos não coesas, a composição da porosidade total foi semelhante aos solos coesos, porém desde o horizonte superficial o volume de microporos foi maior, atestando o comprometimento desses solos em relação ao volume vazio, que seria preenchido por ar. Considerando o histórico de uso dessas áreas, justifica-se o volume de microporos em detrimento aos macroporos.

Quanto à disponibilidade de água, nota-se que nos solos coesos a quantidade de água retida entre a capacidade de campo e o ponto de murcha permanente foi maior que na província de solos não coesos. Esse resultado demonstra que de certa forma trata-se de um sistema conservativo de água, ou seja, as perdas de água por percolação devem se dar de forma mais lenta principalmente por causa da maior quantidade de microporos.

TABELA 4 - Resultados físico-hídricos de solos coesos e não coesos em terço superior e inferior de encostas, município de Itaboraí/RJ゙.

\begin{tabular}{|c|c|c|c|c|c|c|c|c|c|}
\hline \multirow{2}{*}{\multicolumn{2}{|c|}{ Horizonte }} & \multirow{3}{*}{$\begin{array}{c}\text { Ds } \\
\mathrm{Mg} \mathrm{m}^{-3}\end{array}$} & \multirow{3}{*}{$\begin{array}{c}\mathrm{KS} \\
\mathrm{cm} \mathrm{h}^{-1}\end{array}$} & \multicolumn{4}{|c|}{ porosidade } & \multirow{3}{*}{$\begin{array}{c}\text { cap. } \\
\text { campo }\end{array}$} & \multirow{3}{*}{$\begin{array}{l}\text { água } \\
\text { disp. }\end{array}$} \\
\hline & & & & total & macro & micro & aeração & & \\
\hline Simb & Prof. (cm) & & & \multicolumn{4}{|c|}{$\mathrm{m}^{3} \mathrm{~m}^{-3}$} & & \\
\hline \multicolumn{10}{|c|}{ Pedossequência 01 - Perfil 01 (PAx) - Terço superior } \\
\hline Ap & $0-18$ & 1,28 & 37,7 & 0,54 & 0,22 & 0,32 & 0,23 & 0,30 & 0,04 \\
\hline $\mathrm{BAt}_{\mathrm{x}}$ & $18-32$ & 1,78 & 0,8 & 0,40 & 0,06 & 0,34 & 0,09 & 0,31 & 0,08 \\
\hline $\mathrm{Btx}_{1}$ & $32-61$ & 1,78 & 0,5 & 0,39 & 0,05 & 0,34 & 0,07 & 0,32 & 0,07 \\
\hline $\mathrm{Btx}_{2}$ & $61-75^{+}$ & 1,77 & 0,6 & 0,40 & 0,03 & 0,37 & 0,06 & 0,34 & 0,06 \\
\hline \multicolumn{10}{|c|}{ Pedossequência 01 - Perfil 02 (LAx) - Terço inferior } \\
\hline$A p$ & $0-22$ & 1,52 & 5,66 & 0,49 & 0,07 & 0,42 & 0,12 & 0,36 & 0,05 \\
\hline$B A x$ & $22-36$ & 1,58 & 2,35 & 0,42 & 0,01 & 0,40 & 0,10 & 0,31 & 0,05 \\
\hline$B w x_{1}$ & $36-74$ & 1,57 & 2,62 & 0,41 & 0,01 & 0,40 & 0,11 & 0,30 & 0,06 \\
\hline$B w x_{2}$ & $74-102^{+}$ & 1,52 & 1,66 & 0,47 & 0,02 & 0,44 & 0,15 & 0,32 & 0,08 \\
\hline \multicolumn{10}{|c|}{ Pedossequência 02-Perfil 03 (PVA) - Terço superior } \\
\hline Ap & $0-11$ & 1,30 & 0,89 & 0,51 & 0,09 & 0,52 & 0,10 & 0,41 & 0,03 \\
\hline BA & $11-34$ & 1,42 & 0,71 & 0,47 & 0,08 & 0,37 & 0,10 & 0,37 & 0,03 \\
\hline $\mathrm{Bt}_{1}$ & $34-55$ & 1,29 & 3,75 & 0,49 & 0,93 & 0,37 & 0,12 & 0,37 & 0,03 \\
\hline $\mathrm{Bt}_{2}$ & $55-98^{+}$ & 1,31 & 4,93 & 0,52 & 0,12 & 0,42 & 0,13 & 0,38 & 0,04 \\
\hline \multicolumn{10}{|c|}{ Pedossequência 02- Perfil 04 (PVA) - Terço inferior } \\
\hline$A p$ & $0-16$ & 1,50 & 0,87 & 0,50 & 0,01 & 0,45 & 0,06 & 0,44 & 0,05 \\
\hline BA & $16-40$ & 1,46 & 1,62 & 0,48 & 0,06 & 0,38 & 0,07 & 0,41 & 0,05 \\
\hline $\mathrm{Bt}_{1}$ & $40-65$ & 1,22 & 4,65 & 0,52 & 0,01 & 0,41 & 0,12 & 0,39 & 0,05 \\
\hline $\mathrm{Bt}_{2}$ & $65-113^{+}$ & 1,34 & 5,42 & 0,51 & 0,08 & 0,41 & 0,08 & 0,42 & 0,04 \\
\hline
\end{tabular}


A condutividade hidráulica saturada (KS) é um parâmetro muito utilizado para identificação de horizontes coesos. As diferenças no KS foram destacadas entre os horizontes, sendo menor nos subsuperficiais das classes coesas, principalmente no terço superior em relação ao inferior. $E$ nos não coesos, houve um aumento desse valor em profundidade em ambos perfis.

Esses resultados são condizentes com a limitação da coesão, mais fortemente em solos situados na posição mais alta da encosta. É importante ressaltar que diferente do que aconteceu nos perfis 1 e 2 (coesos), nos perfis 3 e 4 (não coesos) a variabilidade desse parâmetro foi menor.

Nesses solos há indícios de compactação no horizonte superficial, seja pelo pisoteio do gado como também resquícios do manejo pretérito do solo com mecanização denominado como "pé de arado", que geralmente se estabelece logo abaixo da camada arada, cerca de $30 \mathrm{~cm}$ de profundidade (FERREIRA et al., 2010; MONTANARI et al., 2012) (Figura 2).

As diferenças encontradas nos atributos físicos, principalmente densidade e condutividade hidráulica saturada, também podem estar relacionadas com os diferentes graus de estrutura entre os solos coesos e não coesos e também pelas diferenças texturais sendo uma mais argilosa que a outra. Ademais, as diferenças na declividade das duas áreas podem estar favorecendo a translocação de materiais coloidais do terço superior para o inferior e ainda em profundidade dentro do perfil.

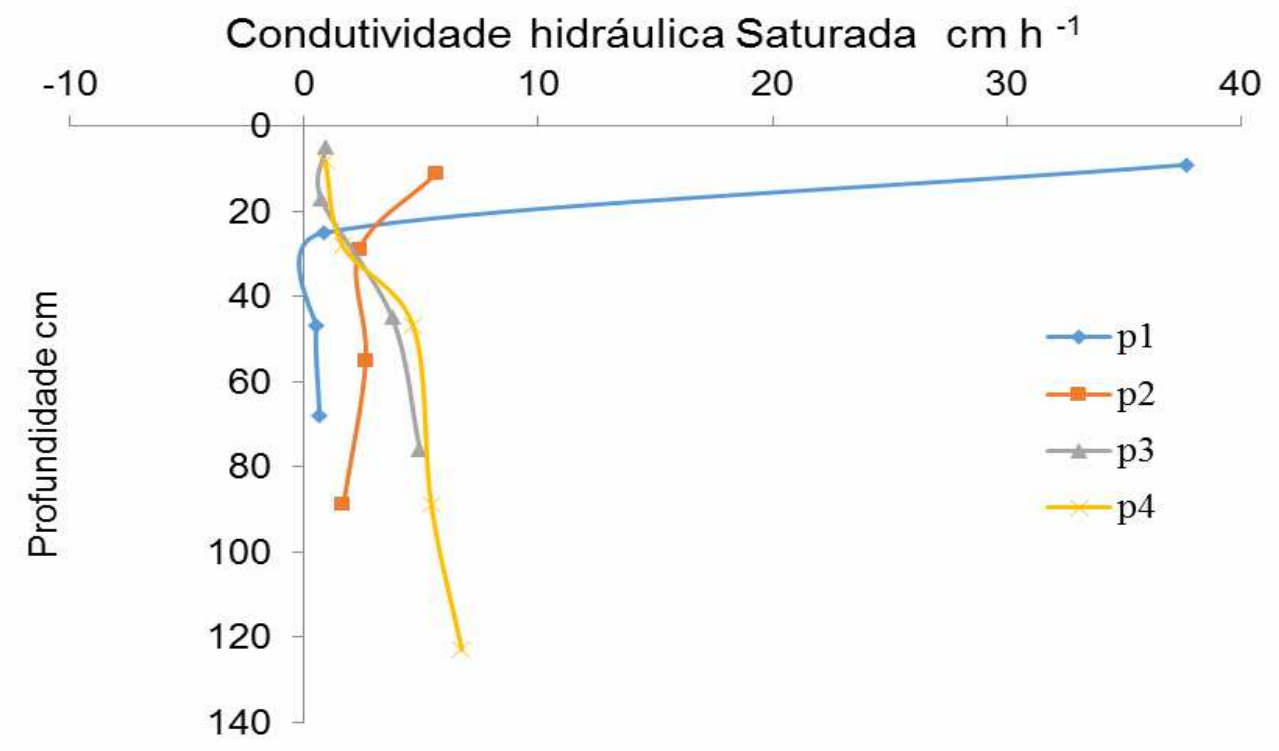

FIGURA 2 - Condutividade hidráulica $\mathrm{cm} \mathrm{h}^{-1}$ de solos coesos ( $\mathrm{p} 1$ terço superior e $\mathrm{p} 2$ terço inferior), e não coesos (p3 terço superior e p4 terço inferior).

\section{Estimativa da capacidade de campo e água disponível considerando diferentes porosidades de aeração}

Quanto à disponibilidade de água, os valores verificados pelos extratores foram superestimados, para todos os horizontes e perfis (Tabela 5). Esse resultado está relacionado com a quantidade de porosidade de aeração na capacidade de 
campo, que está sempre abaixo do mínimo estabelecido pela literatura para a maioria das plantas cultivadas.

A capacidade de campo é definida como a quantidade de água retida pelo solo depois que o excesso tenha sido drenado e a taxa de movimento descendente tenha decrescido acentuadamente, o que geralmente ocorre dois a três dias depois de uma chuva ou irrigação em solos permeáveis de estrutura e textura uniformes, ou seja, nesse momento já se estabeleceu uma porosidade de aeração mínima de $10 \%$ a $15 \%$ do volume total de poros (DEDECEK et al., 2014).

No caso dos solos estudados foi considerando $10 \mathrm{kPa}$ a pressão correspondente para a capacidade de campo, porém a porosidade de aeração em todos os horizontes com exceção apenas do superficial do solo coeso no terço superior foram inferiores ao limite mínimo de 10\%. O mesmo comportamento foi observado nos horizontes superficiais do solo não coeso no terço inferior (Tabela 5).

Em contrapartida, se considerarmos a porosidade de aeração como sendo $15 \%$, todos os horizontes dos perfis coesos e não coesos apresentaram na capacidade de campo, volume de ar inferior. A única exceção foi para o horizonte A do solo coeso de terço superior (Tabela 5), ou seja, a maioria dos horizontes não encontra equilíbrio entre a quantidade de água e ar, em outras palavras, quando começa a ter porosidade de aeração ideal para a realização das funções vitais da planta, não se tem mais água.

Porém, esse resultado indica que solos coesos de terço superior apresentam maior limitação que os de terço inferior, resultado semelhante ao encontrado por VIEIRA et al. (2012). Porém, vale ressaltar que a dificuldade de disponibilizar água indica menor movimento dela dentro do perfil, o que nos leva a induzir que de certa forma, as perdas de água e nutrientes ocorrerão de forma mais lenta, caracterizando um sistema conservativo.

Nos solos não coesos, essa limitação começa nos horizontes superficiais (VIEIRA et al., 2012), demonstrando que a camada superior já apresenta características físicas de um solo degradado. Na área onde foram abertos os perfis, o terço inferior muitas vezes estava em fase soterrada, e ainda era visível a compactação superficial, resultado do uso intenso dessas áreas, principalmente no terço inferior, cujo acesso é mais facilitado, considerando que nessas áreas a declividade é bastante elevada.

Desta forma, os fluxos hídricos dentro dos perfis são maiores nos solos não coesos, ou seja, a drenagem é mais facilitada nesses grupos de solos. Enquanto que na província dos solos coesos, os fluxos se dão de maneira mais retardada, favorecendo uma drenagem mais dificultada, que de certa forma, ameniza a coesão dos horizontes dos solos que estão em posição mais rebaixada na paisagem. Essa característica de sistema conservativo é ocasionada principalmente pela maior presença de microporos, pela dificuldade de drenagem (menor KS), maior densidade caráteres típico de solos coesos. Ressaltando ainda que esses processos são mais acentuados no terço superior do que no inferior.

O grande desafio é que esses horizontes interferem na dinâmica da água, no crescimento de raízes e, consequentemente, na nutrição mineral das plantas (CORRÊA et al., 2015), trazendo muitos problemas para os agricultores donos de terras dentro da província coesa do Brasil. 
TABELA 5 - Resultados da capacidade de campo e água disponível considerando diferentes porosidades de aeração em horizontes de solos coesos e não coesos em duas posições na paisagem no município de Itaboraí-RJ゙.

\begin{tabular}{|c|c|c|c|c|c|c|c|c|c|c|}
\hline \multicolumn{2}{|c|}{ Horizonte } & \multirow[t]{2}{*}{ PT } & \multirow[t]{2}{*}{$\begin{array}{c}\text { Aeração } \\
\text { verificada }\end{array}$} & \multirow[t]{2}{*}{$\begin{array}{c}\text { CC } \\
\text { Verificada } \\
10 \mathrm{kPa}\end{array}$} & \multirow[t]{2}{*}{$\begin{array}{c}\text { AD } \\
\text { Verificada } \\
\text { (CC-PMP) }\end{array}$} & \multirow{2}{*}{$\begin{array}{c}\mathrm{CC} \\
10 \\
\mathrm{~m}^{3} \mathrm{~m}^{-3} \\
\end{array}$} & \multirow[t]{2}{*}{$\begin{array}{l}\text { CC } \\
15\end{array}$} & \multirow[t]{2}{*}{$\begin{array}{c}A D \\
10\end{array}$} & \multirow[t]{2}{*}{$\begin{array}{l}A D \\
15\end{array}$} & \multirow[t]{2}{*}{ PMP } \\
\hline $\operatorname{simb}$ & Prof. (cm) & & & & & & & & & \\
\hline \multicolumn{11}{|c|}{ Pedossequência 01 - Perfil 01 (PAx) - Terço superior } \\
\hline Ap & $0-18$ & 0,54 & 0,23 & 0,04 & 0,04 & 0,44 & 0,39 & 0,18 & 0,12 & 0,26 \\
\hline$B A x$ & $18-32$ & 0,40 & 0,09 & 0,08 & 0,08 & 0,30 & 0,25 & 0,07 & 0,02 & 0,23 \\
\hline $\mathrm{Btx}_{1}$ & $32-61$ & 0,39 & 0,07 & 0,07 & 0,07 & 0,29 & 0,24 & 0,03 & 0,00 & 0,26 \\
\hline $\mathrm{Btx}_{2}$ & $61-75^{+}$ & 0,40 & 0,06 & 0,06 & 0,06 & 0,30 & 0,25 & 0,02 & 0,00 & 0,28 \\
\hline \multicolumn{11}{|c|}{ Pedossequência 01 - Perfil 02 (LAx) - Terço inferior } \\
\hline Ap & $0-22$ & 0,49 & 0,12 & 0,05 & 0,05 & 0,39 & 0,39 & 0,07 & 0,05 & 0,32 \\
\hline$B A x$ & $22-36$ & 0,42 & 0,10 & 0,05 & 0,05 & 0,32 & 0,23 & 0,06 & 0,00 & 0,26 \\
\hline$B w x_{1}$ & $36-74$ & 0,41 & 0,11 & 0,06 & 0,06 & 0,31 & 0,24 & 0,07 & 0,00 & 0,24 \\
\hline$B w x_{2}$ & $74-102^{+}$ & 0,47 & 0,15 & 0,08 & 0,08 & 0,37 & 0,28 & 0,12 & 0,00 & 0,25 \\
\hline \multicolumn{11}{|c|}{ Pedossequência 02 - Perfil 03 (PVA) - Terço superior } \\
\hline Ap & $0-11$ & 0,51 & 0,10 & 0,03 & 0,03 & 0,41 & 0,37 & 0,07 & 0,00 & 0,34 \\
\hline BA & $11-34$ & 0,47 & 0,10 & 0,03 & 0,03 & 0,37 & 0,33 & 0,10 & 0,00 & 0,27 \\
\hline $\mathrm{Bt}_{1}$ & $34-55$ & 0,49 & 0,12 & 0,03 & 0,03 & 0,39 & 0,35 & 0,11 & 0,01 & 0,28 \\
\hline $\mathrm{Bt}_{2}$ & $55-98^{+}$ & 0,52 & 0,13 & 0,04 & 0,04 & 0,42 & 0,37 & 0,12 & 0,03 & 0,30 \\
\hline \multicolumn{11}{|c|}{ Pedossequência 02 - Perfil 04 (PVA) - Terço inferior } \\
\hline Ap & $0-16$ & 0,50 & 0,06 & 0,05 & 0,05 & 0,40 & 0,35 & 0,06 & 0,00 & 0,34 \\
\hline BA & $16-40$ & 0,48 & 0,07 & 0,05 & 0,05 & 0,38 & 0,33 & 0,10 & 0,00 & 0,28 \\
\hline $\mathrm{Bt}_{1}$ & $40-65$ & 0,52 & 0,12 & 0,05 & 0,05 & 0,42 & 0,04 & 0,16 & 0,03 & 0,26 \\
\hline $\mathrm{Bt}_{2}$ & $65-113^{+}$ & 0,51 & 0,13 & 0,42 & 0,31 & 0,41 & 0,08 & 0,10 & 0,00 & 0,31 \\
\hline
\end{tabular}

* PT: porosidade total; Aeração: porosidade de aeração verificada; CC: capacidade de campo; AD água disponível; PMP: ponto de murcha permanente; CC10: capacidade de campo menos 10\% de porosidade de aeração; CC15: capacidade campo menos 15\% de porosidade de aeração; AD10: CC10-PMP; AD15: CC15-PMP. 


\section{CONCLUSÕES}

Os solos apresentaram características morfológicas, físicas e químicas distintas e essas variações podem estar sendo influenciadas pelo relevo e consequentemente pela granulometria dos solos derivados de geologias distintas.

Os Latossolos Amarelos Distrocoesos apresentaram características físicohídricas e morfológicas típicas de solos coesos.

Há variabilidade nos atributos físicos e morfológicos entre os terços superior e inferior nos solos coesos.

Todos os solos apresentaram problemas quanto a disponibilidade de água para plantas, com especial atenção para os Latossolos Amarelos Distrocoesos.

\section{REFERÊNCIAS}

CABRAL, D. de C.; FISZON, J. T. Padrão sócio-espaciais de desflorestamento e suas implicações para fragmentação florestal: estudo de caso na Bacia do Rio Macacu, RJ. Revista Scientia Forestalis, n. 66, p. 13-24, 2004.

CABRAL, D. de C. Floresta, política e trabalho: a exploração das madeiras-de-lei no Recôncavo da Guanabara. Revista Brasileira de História, v. 28, n. 55, p. 217-241, 2008.

CALEGARI, M. R.; MARCOLIN, L. Relação solo - paisagem na bacia da sanga Matilde Cuê, Marechal Cândido Rondon (PR). Boletim de geografia, v. 32, n. 3, p. 110-121, 2014.

CORRÊA, M. M.; KER, J. C.; ARAÚJO FILHO, J. C.; CAMÊLO, D. L. Formas de Ferro, Silício e, ou, Alumínio na Gênese de Fragipãs e Horizontes Coesos dos Tabuleiros Costeiro. Revista Brasileira de Ciência do solo, v. 39, p. 940-949, 2015

DEDECEK, R. A.; RAMOS, M. R.; CURCIO, G. R.; GOMES, J. B. V. Características físico-hídricas. In: RACHEL, B.; PRADO, R. B.; FIDALGO, E. C.; BONNET, A. ed. Monitoramento da revegetação do Comperj: etapa inicial. Brasília: Embrapa, $\mathrm{p}$. 119-137.2014.

EMBRAPA - Empresa Brasileira de Pesquisa Agropecuária. Centro Nacional de Pesquisa de Solos. Manual de métodos de análise de solos. 2.ed. Rio de Janeiro: EMBRAPA, 1997. 209p.

EMBRAPA - EMPRESA BRASILEIRA DE PESQUISA AGROPECUÁRIA.. Sistema Brasileiro de Classificação de Solos, 3ed. rev. ampl. Rio de Janeiro: Embrapa, 2013. 353p.

FERREIRA, R. R. M.; TAVARES FILHO, J.; FERREIRAS, V. M. Efeitos de sistemas de manejo de pastagens nas propriedades físicas do solo. Semina: Ciências Agrárias, v. 31, n. 4, p. 913-932, 2010.

GIAROLA, N. F. B.; SILVA, A. P. Conceitos sobre solos coesos e hardsetting. Scientia Agrícola, v. 59, n. 3, p. 613-620, 2002. 
GIAROLA, N. F. B.; SILVA, A. P.; TORMENA, C.; SOUZA, L. S.; RIBEIRO, L. P. Similaridades entre o caráter coeso dos solos e o comportamento hardsetting: Estudo de caso. Revista Brasileira de Ciência do Solo, v. 25, p. 239-247, 2001.

GOMES, J. B. V.; ARAÚJO FILHO, J. C.; CURI, N. Solos de tabuleiros costeiros sob florestas naturais e sob cultivo. Pesquisa Florestal Brasileira, v. 32, n. 71, p. 233246, 2012.

GOMES, J. B, V.; CURCIO G. R.; DEDECEK, R. A.; RAMOS, M. R. Atributos dos solos do complexo petroquímico Comperj em função de variações litotípicas, da paisagem e do uso atual. Pesquisa Florestal Brasileira, v. 34, n. 77, p. 1-11, 2014.

GONÇALVES, A. O. Caracterização climática. In RACHEL B.; PRADO, R. B.; FIDALGO, E. C. C. F.; BONNET, A. (ed). Monitoramento da revegetação do Comperj: etapa inicial. Brasília: Embrapa, p. 65-82.2014.

GUEDES FILHO, O.; SILVA, A. P. da; GIAROLA, N. F. B.; TORMENA, C. A. Permeabilidade ao ar da cama de semeadura do solo em sistema de Semeadura direta. Revista Brasileira de Ciência do Solo, v.39, p.841-851, 2015.

LIMA, H. V.; SILVA, A. P.; JACOMINE, P. T. K.; ROMERO, R. E.; LIBARDI, P. L. L. Identificação e caracterização de solos coesos no Estado do Ceará. Revista Brasileira de Ciência do Solo, v. 28, p. 467-476, 2004.

LIMA NETO, J. A.; RIBEIRO, M. R.; CORRÊA, M. M.; SOUZA-JÚNIOR, V. S.; ARAÚJO FILHO, J. C.; LIMA, J. F. W. F. Atributos químicos, mineralógicos e micromorfológicos de horizontes coesos de Latossolos e Argissolos dos Tabuleiros Costeiros do estado de Alagoas. Revista Brasileira de Ciência do Solo, v. 34, n. 02, p. 473-486, 2010.

MONTANARI, R.; ZAMBIANCO, E. C.; CORRÊA, A. R. PELLIN, D. M. P.; CARVALHO, M. P.; DALCHIAVON, F. C. Atributos físicos de um Latossolo Vermelho correlacionados linear e espacialmente com a consorciação de guandu com milheto.

Revista Ceres, v. 59, n. 1, p. 125-135, 2012

MORAIS, R. M. O.; MELLO, C. L.; COSTA, F. O.; SANTOS, P. F.; SANTOS, P. F. Fácies Sedimentares e Ambientes Deposicionais Associados aos Depósitos da Formação Barreiras no Estado do Rio de Janeiro. Revista do Instituto de Geociências. Geologia USP Série Científica, v. 6, p. 19-30, 2006.

MOREAU, A. M. S. dos S.; KER, J. C.; COSTA, L. M. da; GOMES, F. H. Caracterização de solos de duas topossequências em tabuleiros costeiros do sul da Bahia. Revista Brasileira de Ciência do Solo, v. 30, p. 1007-1019, 2006.

RAMOS, M. R.; CURCIO, G. R.; DEDECEK, R. A.; MELO, V. F.; UHLMANN, A. Influência da posição na encosta na manifestação do caráter coeso em solos da Formação Macacu, no Estado do Rio de Janeiro. Revista Brasileira de Ciência do Solo, v. 37, p. 837-845, 2013. 
RIBEIRO, L. P. Uma visão pedogenética trasncontinental da formação Barreiras: Um novo paradigma? Revista Magistra, v. 19, p. 89-97, 2007.

RICCOMINI C.; SANT`ANA, L. G.; FERRARI, A. L.; Evolução geológica do Rift Continental do Sudeste do Brasil. In: MANTESSO-NETO, V.; BARTORELLI, A.; CARNEIRO, C. D. R.; BRITO-NEVES, B. B. Geologia do Continente SulAmericano: Evolução da obra de Fernando Flávio Marques de Almeida.p. 383405.2004.

SANTOS, R. D.; LEMOS, R. C.; SANTOS, H. G.; KER, J. C. ANJOS, L. H. C. Manual de descrição e coleta de solo no campo. 5.ed. Viçosa: Sociedade Brasileira de Ciência do Solo, 2005, 100p.

SILVA, A. de P.; GONÇALVEZ, F. L. A.; de AZEVEDO, J. N.; OLIVEIRA, N. M.; JANTALIA, C. P.; CAMPELLO, E. F. C; RESENDE, A. S. Biomassa vegetal em áreas de pastagem e na serapilheira de florestas. In: RACHEL, B.; PRADO, R. B.; FIDALGO, E. C. BONNET, A. (ed). Monitoramento da revegetação do Comperj: etapa inicial. Brasília: Embrapa, p. 177-186.2014.

SILVA, L.; EMER, A. A.; BORTOLINI, C. E.; ARRUDA, J. H. Estudo de um Nitossolo Vermelho com evidencia de caráter coeso da Região Sudoeste do Paraná. Revista Synergismus Scyentifica, v. 4, p. 301-304, 2009.

SOUZA, L. S.; SOUZA, L. D.; PAIVA, A. Q.; RODRIGUES, C. V.; RIBEIRO, L. S. Distribuição do sistema radicular de citros em uma topossequência de solos de Tabuleiros Costeiros do Estado da Bahia. Revista Brasileira de Ciência do Solo, v. 23, p. 503-513, 2008.

USDA. Soil Survey Manual. Washington: Soil conservation service. U. S. Departament of Agriculture. Washingotn DC, USDA, 1993, 437p.

VIEIRA, J. M.; ROMERO, R. E.; FERREIRA, T. O.; de ASSIS JR, R. N. Contribuição de material amorfo na gênese de horizontes coesos em Argissolos dos Tabuleiros Costeiros do Ceará. Revista Ciência Agronômica, v. 43, n. 4, p. 623-632, 2012. 